\title{
O SEMblante, O CORPO E O OBJETO ${ }^{\star}$
}

\author{
Giselle Falbo Kosovski ${ }^{\star}$
}

\begin{abstract}
Resumo
Partindo da articulação entre os termos semblante, corpo e objeto na teoria psicanalítica, a finalidade deste texto é "discutir" o corpo na Teoria dos Discursos. Para tanto, procuramos explicitar melhor a função do objeto perdido tal como é recolhida por Lacan do texto freudiano, visando estabelecer o estatuto do objeto que sustenta a imagem e sua relação com o gozo - entendido neste contexto como satisfação que transcende os limites estabelecidos pelo prazer como princípio.
\end{abstract}

Palavras-chave: psicanálise; corpo; semblante; objeto; sujeito.

\section{THE FACE, THE BODY AND THE OBJETC}

\begin{abstract}
Based on the relationship between the terms face, body and object in psychoanalytic theory, the purpose of this paper is try to situate the body in the Theory of Discourses. In this direction, we intent to clarify the function of the lost object, as collected by Lacan from freudian's text, to establish the status of the object that supports the image and its relation to the enjoyment-understood here as satisfaction that transcends the limits of pleasure as a principle.
\end{abstract}

Keywords: Psychoanalysis; body; face; object; subject.

\footnotetext{
^Este texto é um desenvolvimento das idéias inicialmente apresentadas na tese de doutorado defendida em 2003, na Universidade Federal do Rio de Janeiro. E seu conteúdo foi parcialmente apresentado nas Jornadas da Escola Brasileira de Psicanálise (EBP) em 2010.

$\star \star$ Psicóloga. Psicanalista. Doutora em Teoria Psicanalítica pela Universidade Federal do Rio de Janeiro. Atualmente é Professora Adjunta da Universidade Federal Fluminense na qual desenvolve a pesquisa: O que a arte ensina para a psicanálise?. Endereço: Universidade Federal Fluminense, Instituto de Ciências Humanas e Filosofia. Campus do Gragoatá, s/no ${ }^{\circ}$, Bloco O, sala 222. São Domingos - Niterói, RJ. CEP: 24210-350. Brasil.

E-mail: gifalbo@centroin.com.br
} 
"As pulsões são, no corpo, o eco do fato de que há um dizer" (LACAN, 2007[1975-1976], p. 18).

\section{ApresentaÇão}

Este escrito é resultado de uma pesquisa mais ampla que estamos realizando em torno do estatuto do corpo em psicanálise. Partindo da articulação entre semblante, corpo e objeto, a finalidade deste texto é - na tensão entre saber e verdade - procurar indicar o corpo na Teoria dos Discursos. A discussão aqui proposta toma como solo o Discurso do Mestre, por ser - como explicita Lacan (1992[1969-1970]) em "O avesso da psicanálise" - não somente aquele que funda a cadeia discursiva, mas também o lugar no qual se demonstra a própria torção empreendida pelo Discurso do Psicanalista.

No primeiro tempo do estudo que deu ensejo a este texto, através da leitura do Seminário XXIII (LACAN, 2007[1975-1976]), procuramos situar os diferentes modos de constituir o corpo próprio (FALBO; FREIRE, 2009). Deste caminho, tendo Joyce como eixo e contraponto, recolhemos a indicação de Lacan de que o ego é a idéia que temos de nós mesmos como um corpo (LACAN, (2007[19751976], p. 146); e que se este é dito narcísico, é porque, em certo nível, há alguma coisa que suporta o corpo como imagem. Isso que suporta a imagem é como um oco, uma hiância que certo número de objetos - a voz, o seio, as fezes e o olhar - vêm preencher servindo lhe como tampão. A idéia de que há um ossobjeto (LACAN, 2007[1975-1976]) que suporta a imagem já havia sido enunciada por Lacan, em outros termos, alguns anos antes:

É no nível do além do princípio do prazer que Freud marca com força que o que em última instância constitui o verdadeiro sustentáculo, a consistência da imagem especular do aparelho do eu, é o fato de que este é sustentado no interior por esse objeto perdido, que ele apenas veste, por onde o gozo se introduz na dimensão do ser do sujeito (LACAN, 1992[1969-1970], p. 47).

Para introduzir a discussão em torno da relação entre o semblante e o corpo será preciso, portanto, explicitar melhor a função do objeto perdido tal como é recolhida por Lacan do texto freudiano, visando estabelecer o estatuto do objeto que sustenta a imagem e sua relação com o gozo - entendido neste contexto como satisfação que transcende os limites estabelecidos pelo prazer como princípio.

\section{A REPETIÇÃo, O OBJETO PERDIDO E O OBJETO $a$}

Com o objetivo de situar o suporte da imagem - imagem esta que também funciona como um representante que se fará significante de um sujeito para outro significante - nos voltamos para a leitura que Lacan faz das formulações freudianas sobre a repetição, tendo em vista que, em Freud, o sentido específico da repetição no ser falante é algo muito diferente da memória tal como concebida pela biologia, posto que esta aponta para os limites do saber. Como 
foi dito, a discussão em torno da compulsão à repetição é o que introduz a função do objeto desde sempre perdido em Freud, através da qual Lacan elabora o conceito de objeto $a$ : aquilo que resta da operação significante, sustentando a imagem de si como corpo próprio. A partir destas formulações, nosso passo seguinte será indicar como se articulam a repetição que visa o traço unário, o gozo e o objeto na Teoria dos Discursos.

No ensino de Lacan, a repetição é uma denotação precisa do traço unário: elemento de escrita, traço na medida em que este comemora a irrupção de um gozo. Sobre a repetição, Lacan (1992[1969-1970]) nos diz que, no nível elementar - aquele da imposição do traço unário - o saber em trabalho produz entropia. Isto porque o que se repete jamais pode estar em relação ao que se pretende repetir, senão em perda. Se a repetição fosse pura igualdade, um traço não se articularia a outro posto que haveria entre eles plena identidade.

Para que o traço possa se tornar significante, há que haver diferença, sem a qual não se estabelece oposição. E é pela oposição que se estabelece entre a inscrição do traço e aquilo que se encontra na procura pela identidade, que o traço unário poderá se estabelecer, a posteriori - por sua oposição ao segundo traço como primeiro significante: S1. Em outras palavras, o Um só se estabelece como significante em um momento que é só-depois, pela retroação do segundo sobre o que ainda não havia se constituído como primeiro, seguindo a temporalidade característica dos processos inconsciente. É o segundo, portanto, que estabelece o traço unário como inscrição significante. Como decorrência, para que o laço entre o Um e o Outro se estabeleça, é imprescindível situar a ausência de identidade. Uma identidade almejada na busca empreendida pela repetição que projeta o gozo sempre além, mais ainda.

Esta diferença de satisfação introduz o anseio pelo que poderia vir a completá-la, um objeto que na verdade não há: o objeto desde sempre perdido. No seminário “A ética da psicanálise” (LACAN, 1997[1959-1960], p. 149), através de uma frase atribuída a Picasso, Lacan explicita o estatuto do objeto em questão: "eu não procuro, encontro". Frase que ele utiliza como expressão da essência do conceito de objeto tal como formulado por Freud em relação ao funcionamento do psiquismo: a concepção de objeto como (re) encontro. Encontro que - nos termos do seminário "Os quatro conceitos fundamentais da psicanálise" (LACAN, 1988[1964]) - só ocorre como “Tique”, o mau encontro que desvela e institui o objeto como nostalgia.

Este conceito de objeto é a encarnação de um paradoxo já que, por natureza, ele é sempre reencontrado, embora nunca tenha sido de fato perdido. Ser significado como perdido - como falta - é conseqüência deste "só-depois". Por este motivo, o único modo de se saber perdido é por meio dos reencontros: é o reencontro que estabelece o objeto como perda - como negatividade. Em si mesmo, o objeto em questão é pura ausência de identidade e de predicação. Por sua vez, em relação à busca que tem como causa o objeto perdido, Lacan (1997[1959-1960]) observa que, embora estranho ao significante, aquilo que é achado sempre é procurado em suas malhas; o que faz desta procura uma busca anti-psíquica já que, por seu 
lugar e função, ela se dirige para além do princípio do prazer: o gozo. Esta busca anti-psíquica se dá na medida em que, "segundo as leis do princípio do prazer, o significante projeta, neste para além, a homeostase". (LACAN, 1997[1959-1960], p.149) Uma homeostase que, em sua radicalidade - tal como deduzida por Freud (1975[1920]) de sua experiência com a clínica - será nomeada "pulsão de morte".

É em relação a estes termos que, dez anos depois de o seminário sobre a ética, Lacan (1992[1969-1970]) discute mais uma vez a função do traço unário: forma mais simples da marca e origem do significante. Este saber situado na origem indica, deste modo, sua raiz na repetição - repetição da mesma falha, da mesma ausência de identidade. Sob a forma do traço único, o S1 é tomado, então, como meio de gozo, precisamente por ultrapassar os limites estabelecidos pelo prazer como princípio. É preciso sublinhar que, o que está posto em questão não é a transgressão ou a irrupção em um campo proibido, mas o efeito da entropia: é como desperdício que o gozo se apresenta, como algo que excede e que não serve para nada.

E é exatamente por isto que Lacan (1992[1969-1970]) elege, no Discurso do Mestre, o termo mais-de-gozar para designá-lo: "É justamente por ser apreendido na dimensão da perda - alguma coisa é necessária para compensar, por assim dizer, aquilo que de início é número negativo - que esse não sei que [...] fez gozo, gozo a repetir" (LACAN, 1992[1969-1970], p. 48). É a dimensão da entropia, portanto, que dá corpo ao anseio de que há um mais-de-gozar a ser recuperado. Tal como o objeto desde sempre perdido, o objeto $a$, em si, marca apenas a ausência de identidade e de predicação, pura diferença. Contudo, ele ganha outros valores e funções, a depender de sua posição no discurso, sendo esta uma das novidades que Lacan introduz em relação ao que originalmente havia sido talhado por Freud.

Ainda em relação ao problema posto pelo traço e por sua articulação na cadeia, Lacan (2007[1975-1976]) dirá que o homem é um composto trinitário de elementos. Um elemento é o que faz um, ou seja, o que faz traço unário. E o que faz Um incita à substituição, posto que a característica de um elemento é que ele instaura a combinatória de elementos. Este significante unário se inclina, contudo, sempre na direção de estabelecer-se como universo - um único verso, tendência que se sustenta no mito de que este invólucro, este saco, consiste na esfera perfeita. Valendo-se da metáfora do saco Lacan nos adverte, em contrapartida, que para que o saco possa se fechar faz-se necessária a amarração de uma corda, sem a qual isto não se enoda.

Para além de sua suposta integralidade, portanto, o S1 não constitui o Um da unidade. Pelo contrário, ele o indica como podendo nada conter e, neste sentido, o S1 é homólogo ao objeto $a$. Aqui, o Um é indicado como podendo ser um saco vazio - um corpo sem órgãos. Nota-se que, nem por isto, um saco vazio permanece um saco: isso que só é imaginável pela ex-sistencia e pela consistência que o corpo tem, de ser pote. Tais reflexões indicam que este S1 não é necessariamente uma face, um semblante, tal como nos induz a pensar a dimensão 
imaginária. Para além do que se estabelece como ego - imagem que fazemos de nós mesmos como um corpo - trata-se aí, sobretudo, de um fio, algo que faz nó, estabelecendo a cadeia articulada de termos sem a qual o sujeito não se sustenta.

$\mathrm{Na}$ neurose, para que este primeiro significante possa se constituir como imagem do corpo unificado - imagem que é também significante - faz-se necessária a alienação do sujeito a este S1. Como Freud (1975[1914]) elucida através da reflexão sobre o narcisismo, esta operação se dá através uma nova ação psíquica que estabelece o amor de si mesmo e que situa o eu na posição de objeto, objeto de investimento libidinal. O que faz do corpo algo que não se é e, tampouco, se tem exatamente. Nota-se aqui uma dimensão da divisão que concerne à relação do sujeito com o corpo, algo que vacila entre dois pólos: o ser e o ter. Tal como indica o uso da expressão linguageira, "meu corpo", apesar da importância da identificação à imagem que estabelece a dimensão imaginária do eu - o ego não nos aderimos integralmente a ela, o que nos indica sua face de objeto.

Lembramos que esta face do eu na qual ele se desvela objeto foi precisamente o que conduziu Freud a incorporar o narcisismo ao léxico dos termos psicanalíticos, desestabilizando seu edifício teórico. Desestabilização que abriu flanco para a revisão posterior da teoria das pulsões e que só se resolve com a torção que edifica o conceito de pulsão de morte e a proposição do masoquismo como originário. Nota-se que a repetição do mesmo fracasso - à qual vínhamos nos referindo quando abordamos a concepção do objeto como desde sempre perdido - está estreitamente correlaciona ao conceito de masoquismo, entendido como busca de um gozo ruidoso que nos remete à satisfação fruída pelo sujeito ao colocar-se na posição de objeto de gozo do Outro, de um gozo suposto ao Outro que, na verdade, não existe.

\section{IMAGEM E CORPO}

Tendo estabelecido estas considerações iniciais, e proposto uma articulação entre o ensino sobre "O sinthoma" (LACAN, 2007[1975-76]) e o estudo do estádio do espelho (LACAN, 1998[1938]), concluímos que a dimensão imaginária não recobre integralmente o corpo que, em essência, é um $a$ recortado e vestido pela imagem do corpo unificado; imagem construída, no caso da neurose, através de uma nova ação psíquica: o narcisismo, operação regida pela identificação do sujeito a sua imagem como corpo unificado.

Destacamos que para que o significante S1 possa representar o sujeito e, deste modo, venha a adquirir valor de representante, faz-se necessária que esta identificação ao traço único não se dê como colagem absoluta. O que implica ser imprescindível a produção de uma abertura, sem a qual S1 não poderá funcionar como semblante que se articula no discurso. O S1 na função de semblante já marca uma distância, distância advinda da perda do ser - falta-a-ser. Perda que introduz o ponto não especularizável que descompleta a imagem, em decorrência do qual o sujeito não fica integralmente aderido à imagem, situação que lhe confere a flexibilidade que caracteriza seu deslocamento no espaço aberto à enunciação. 
Revisitando "O estádio do espelho" à luz da teoria dos nós, concluímos que a assunção da imagem de si pode ser entendida como um modo peculiar à neurose de produzir uma amarração que articula os três registros. Isto porque, a edificação da imagem de si - nitidamente marcada pela dimensão imaginária - articula também os outros dois registros: o Real e o Simbólico. O primeiro - o Real - indicado pelo júbilo, gozo fruído no velamento que estabelece os contornos do corpo; e o segundo - o Simbólico - tendo em vista que a identificação a esta imagem de si cumpre também uma função simbólica: representar um sujeito frente a outro significante. Há aqui, portanto, uma das versões possíveis para o enodamento dos três registros, nó sem o qual o sujeito não se sustenta. A edificação do semblante através do qual o sujeito é representado para outro significante é, portanto, uma operação discursiva. E a operação discursiva, conforme pretendemos apresentar a seguir, é não toda significante.

\section{DisCURSO: UMA ESCRITA NÃO TODA SIGNIFICANTE}

O discurso é apresentado por Lacan (1992[1969-1970]) - em "O avesso" - como uma estrutura necessária que ultrapassa em muito a palavra, podendo subsistir sem ela em certas relações fundamentais. Mediante o instrumento da linguagem, instaura-se certo número de relações estáveis - em princípio quatro - no interior das quais se inscreve algo mais amplo e que vai muito além de suas enunciações efetivas. Para Lacan: "os discursos nada mais são do que a articulação significante, o aparelho, cuja mera presença domina tudo o que eventualmente possa surgir em palavras". (LACAN, 1992[1969-1970], p. 158)

O discurso é o que estrutura o mundo real, e sobre suas diferentes configurações se fundam os laços sociais mais fundamentais entre os seres falantes. Segundo Valas (2001), a noção de discurso como laço social mostra que a definição, a distribuição e o manejo do gozo mudam e se ordenam de diferentes modos, em função de cada um dos discursos que condicionam o sujeito. $\mathrm{O}$ discurso não é, portanto, apenas um aparelho de poder, é também um meio de gozo (FALBO, 2003, p.78). Como aparelho, ele só pode ser escrito, e não dito.

A partir dos quatro elementos - S1, S2, sujeito barrado e $a$-constituintes da relação inaugural que institui a linguagem, Lacan propõe um aparelho com quatro lugares: agente (semblante), saber (gozo), produto (perda, mais-de-gozar) e verdade. Por constituir uma estrutura, essa sucessão de quatro letras não pode ser desarrumada e dela resulta, pela operação de um quarto de giro, os quatro discursos fundamentais - Discurso do Mestre (DM), Discurso da Histérica (DH), Discurso do Analista (DA) e Discurso do Universitário (DU). Quando se muda de discurso, as letras trocam de lugar e, conseqüentemente, o que elas designam assume um valor diverso. Reiteramos que o discurso é, acima de tudo, uma escrita, discurso sem palavras. 
Para facilitar a apreensão de nossos argumentos, abaixo apresentamos os matemas dos discursos:

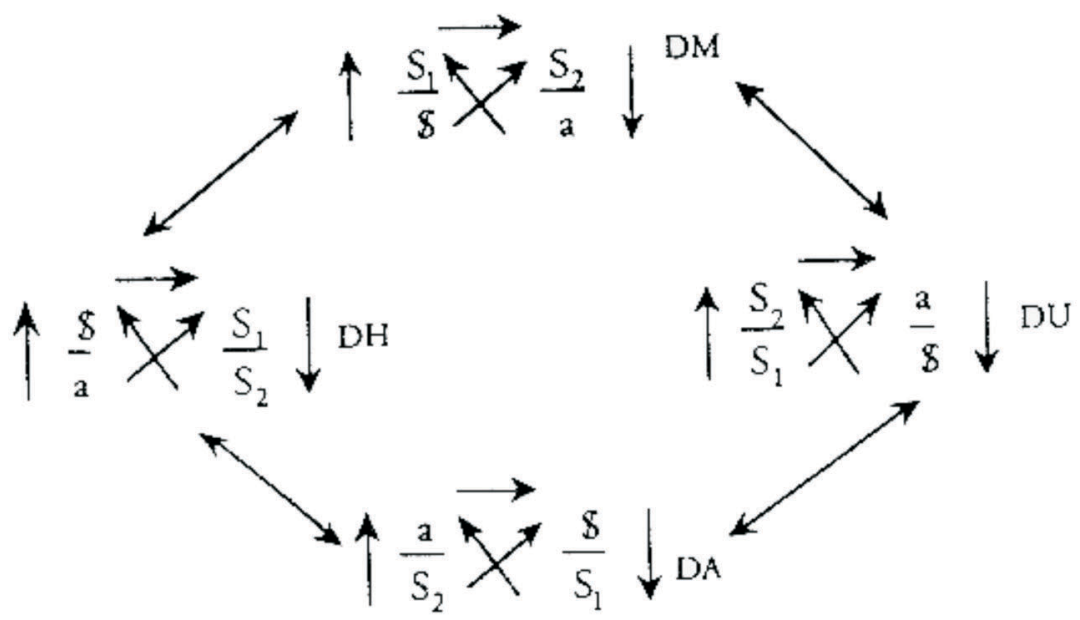

As estruturas discursivas, assim propostas, são definidas em virtude da articulação fundamental do Um (S1) ao Outro (S2), a partir da qual é suposta a emergência de um sujeito. Tal relação parte da definição que Lacan nos fornece do significante: um significante é o que representa um sujeito para outro significante. Desta articulação ele extrai conseqüências fundamentais. No que concerne ao sujeito, o primeiro ponto a enfatizar é que, longe de ser pensado como senhor ou amo do discurso, o sujeito é proposto como puro efeito da inter-significação, ou seja, como conseqüência da estrutura que o determina. Outro aspecto importante é que, no lugar em que é representado pelo significante, o sujeito nunca está: representado, o sujeito é pura divisão e esvanecimento.

De modo diverso da consistência imaginária na qual o eu se encapsula, a definição do significante apresenta o sujeito como pura divisão, uma divisão inexata da qual se precipitará sempre um resto: algo que escapa e simultaneamente articula a cadeia que constitui discurso. Isto que escapa, como demonstrado anteriormente, é uma pura ausência de identidade que movimenta e funciona, tanto como causa de desejo, quanto como "mais-de-gozar", a depender do discurso que estiver em questão. De acordo com Lacan (1992[1969-1970], p. 48), “o a, como tal, é propriamente o que decorre do fato de que o saber, em sua origem, se reduz à articulação significante". Este vazio sem predicação que constitui o objeto não nos é dado naturalmente e, portanto, precisará ser extraído

É importante frisar que a própria definição do significante institui o sujeito como efeito e determina o objeto em uma estrutura que não é toda significante, o que nos autoriza a tentar situar o corpo a partir da teoria dos discursos, indicando-o, no seio da cadeia articulada, como algo para além de suas vertentes imaginária e significante. 
Através da definição de significante, Lacan elabora sua teorização sobre os discursos situando o Discurso do Mestre como fundador da cadeia articulada. Neste discurso, a posição do semblante é ocupada pelo significante S1. O caráter deste lugar na estrutura fica mais bem esclarecido nas primeiras lições do seminário que se segue ao "Avesso" (LACAN, 1992[1969-1970]) - "De um discurso que não fosse semblante" (LACAN, 2009[1971]). O espaço do semblante, além de ser ocupado pelo elemento que irá nomear o discurso - no Discurso da Histeria será ocupado pelo sujeito dividido; no Discurso do Universitário, pelo saber (S2); e no Discurso do Analista pelo objeto causa de saber - indica também "onde se quer chegar" (LACAN, 2009[1971]) em cada uma destas diferentes posições discursivas. Como uma composição que prescinde das palavras para que se apreenda seu sentido, sua direção, o discurso será a estrutura que rege e nos situa na linguagem.

Outro ponto a ser destacado é que, no nível dos discursos, o que está posto em jogo não é a inter-subjetividade, mas a inter-significação. Nesta operação de inter-significação, o significante absoluto constitui uma exterioridade à cadeia já articulada como saber (S2). Trata-se, portanto, de um significante isolado e que, como tal, não mereceria ser designado por este termo - significante - tendo em vista que o mesmo só funciona como tal, por oposição a outros. Como significante situado no ponto de origem, S1 intervém sobre a cadeia já articulada que integra um saber: S2. E é a partir de sua intervenção sobre este campo já estruturado, que S1 irá representar alguma coisa: um sujeito. Em outras palavras, o que é suposto desta relação entre S1 e S2 é um sujeito, na medida em que este é representado por um traço específico, traço que constituirá seu ponto de marca, e também por onde se inseri a questão do gozo. Nesta articulação inicial, para que as coisas aconteçam, andem, o senhor (S1) dá a ordem, o comando. E cumprindo deste modo sua função de amo, ainda que desconhecendo inteiramente esta verdade, ele perde alguma coisa: algo que é da ordem do gozo.

Desta articulação inicial do Um com o Outro algo, destarte, se precipita como perda. Perda que será designada pela letra "a": objeto perdido em torno do qual se organiza toda a dialética da frustração - falta imaginária. Nota-se que $a$ é um elemento não significante, uma letra. No Discurso do Mestre, o objeto perdido é denominado "mais-de-gozar". No contexto apresentado pelo seminário XVII, a expressão "mais-de-gozar" se destina a indicar que aquilo que é perda - o $a$ - é também um espaço aberto, puro corte. Uma hiância que, todavia, não se sabe indicação de perda de gozo: castração. Como vimos anteriormente, o $a$, foi um termo deduzido por Lacan das reflexões freudianas sobre a repetição, e é um elemento que concerne ao saber e a seus limites. O gozo, portanto, nos leva a sair do campo do saber para nos reportamos a seus limites - o que, em Freud, é nomeado pulsão de morte, uma tendência de retorno ao inanimado presente no seio da experiência analítica, que é uma experiência de discurso. 


\section{O SUJEITO E SEMBLANTE NA ESTRUTURA DISCURSIVA}

Retornando ao Discurso do Mestre, é possível verificar que este se edifica sobre o mito ultra-reduzido de ser idêntico a si mesmo, característica que talvez possa ser pensada como herança de sua origem como termo absoluto: uni-verso. E o que resta velado a este significante único é a sua verdade de sujeito dividido. Desta posição, o senhor nada quer saber sobre o desejo, cuja causa se presentifica como resíduo do trabalho do Outro, do escravo.

A partir da teoria dos discursos é possível formular que, solidamente identificado com a imagem de si como corpo, o senhor, um ego forte e autônomo que acredita prescindir do Outro para se fazer representar, comete uma infração lastimável. Creditando todas as fichas na autonomia, na ilusão forjada pelo mito do selfmade-man, o mestre infringe a lei do significante segundo a qual um significante é capaz de significar qualquer coisa, mesmo a si mesmo. Esta é a regra sobre a qual se sustentam as leis da linguagem e que garante o campo aberto à enunciação.

Neste momento, vale dizer algumas palavras acerca da articulação entre o semblante e a verdade, tendo em vista que, por estrutura, a verdade resta sempre velada sob a barra sobre a qual se ergue o semblante; a verdade é o que, em todo discurso, permanece oculto. Nota-se que, embora velada, a verdade guarda sempre articulação com o semblante. Embora o termo "semblante" possa parecer fazer alusão a algo de falso ou mentiroso, é importante frisar que, como artifício de linguagem, o semblante é uma ficção que pode ser portadora da verdade. Na perspectiva da psicanálise - discurso que não fundamenta a referência do discurso à "coisa em si" - o semblante não se opõe necessariamente à verdade. Muito pelo contrário, para se ter acesso à verdade - que sempre se apresenta como semi-dizer - será preciso lançar mão do significante, posto que não há como enunciar "a verdade nua e crua"; até mesmo pelo fato de que, na maior parte das vezes, a verdade não tem nada de belo e recorrentemente solicita um véu que simultaneamente a vele e a sustente.

Como dissemos anteriormente, de acordo com os lugares estabelecidos na estrutura - lugares a serem ocupados pelos elementos (S1, S2, a, sujeito dividido) - a verdade de um discurso está sempre elidida, e tem como face o semblante que indica o rumo em direção ao qual o discurso se inclina. No caso do Discurso do Mestre, a verdade que sustenta a ilusão de mestria é sua realidade de sujeito dividido. Esta posição de mestria não se mantém, contudo, sem que se tenha um preço bastante alto a pagar: o acirrar dos imperativos obscenos e ferozes do supereu. Quanto mais alheio à sua divisão, mais exigente se faz o imperativo categórico, instância que toma o eu como objeto, maltratando-o e incitando-o a gozar.

Para finalizar, resta dizer alguma coisa sobre o corpo: como situá-lo no Discurso do Mestre? Nossa proposta é que o corpo, em sua dimensão real, está indicado pelo " $a$ " situado - nesta posição discursiva - na posição do mais-degozar: uma perda que não se realiza enquanto tal e que, conseqüentemente, não funciona como causa de desejo. Resto que faltaria ao eu, espécie de "algo mais" que o deixa sempre aquém do ideal de perfeição projetado "mais além", configu- 
rando imaginariamente uma esfera sem máculas pela qual são medidas as suas imperfeições e misérias. Por meio da suposta completude que se estabeleceria na fusão ideal do (S1) e o " $a$ ", em uma espécie de jogo de espelhamento, a instância superegóica avalia o eu, aqui reduzido à condição de objeto. Objeto dos maus-tratos com o qual se alimenta o ideal de um gozo sempre além, gozo que se produz como resto no Discurso do mestre.

Para finalizar, deixamos aqui o princípio ético que Lacan recorrentemente endereça aos analistas: Wo es war soll ich werden, como emblemático da torção a ser operada, pelo dispositivo analítico, em relação ao gozo produzido pelo Discurso do Mestre: "É lá onde estava o mais-de-gozar, o gozar do Outro, que eu, na medida em que profiro o ato analítico, devo advir". (LACAN, 1992[1969-1970], p. 62)

\section{REFERÊNCIAS}

FREUD, S. Sobre o narcisismo: uma introdução (1914). In: - Obras Psicológicas Completas de Sigmund Freud. Rio de Janeiro: Imago, 1975. v. XIV, p. 89-122 Edição Standard Brasileira.

FREUD, S. Além do princípio do prazer (1920). In: . Obras Psicológicas Completas de Sigmund Freud. Rio de Janeiro: Imago, 1975. v. XVIII, p. 17-90 Edição Standard Brasileira.

FALBO, G. Para que serve? Quanto vale? Contribuições da psicanálise à reflexão sobre a crise se arte. 2003. Tese (Doutorado) - Universidade Federal do Rio de Janeiro, Rio de Janeiro, 2003.

FALBO, G.; FREIRE, A. B. O corpo como objeto, considerações sobre o conceito de sublimação através da Arte Carnal de Orlan. Aletheia: Revista da Universidade Luterana do Brasil, Curso de Psicologia, Cidade, v. 29, p. 190-203, jan./jun. 2009.

LACAN, J. O estádio do espelho como formador da função do eu (1938). In: . Escritos. Rio de Janeiro: J. Zahar, 1998, p. 96-103.

LACAN, J. O seminário: A ética da Psicanálise (1959-1960), Rio de Janeiro: J. Zahar, 1997. Livro 7.

LACAN, J. O seminário: Os quatro conceitos fundamentais da psicanálise (1964). Rio de Janeiro: J. Zahar, 1988. Livro 11.

LACAN, J. O seminário: O avesso da psicanálise (1969-1970). Rio de Janeiro: J. Zahar, 1992. Livro 17.

LACAN, J. O seminário: O sinthoma (1975-1976). Rio de Janeiro: J. Zahar, 2007. Livro 23. 
LACAN, J. O seminário: De um discurso que não fosse semblante (1971). Rio de Janeiro: J. Zahar, 2009. Livro 18.

VALAS, P. As dimensões do gozo. Rio de Janeiro: J. Zahar, 2001.

Recebido em: abril de 2010

Aceito em: agosto de 2010 

Esteartigo sofreu al terações por solicitação do editor em Dez/2010 conforme ERRATA publicada no Volume 22 Número 3 do periódico. (http://www.scielo.br/pdf/fractal/v22n3/v22n3a01.pdf) 